\title{
Outcome of Dynamic Condylar Screw with Plate versus Distal Femoral Lock Compression Plate Fixation in Fracture of Distal Femur
}

\author{
Md. Gulam Mustofa ${ }^{* 1}$, Chowdhury Foyzur Rob², Md. Kamrul Alam³, Akhlas Bhuiyan, \\ Habibur Rahman Chowdhury ${ }^{5}$, Sahel Ahmed Khan ${ }^{6}$, Tanvir Ahmed ${ }^{7}$
}

\begin{abstract}
Introduction: The dynamic compression screw with plate implant used to treat fractures of the distal femur. The distal femoral lock compression plate fixation is designed as an alternative surgical option to treat these fractures. The objective of this study was to assess the comparative endurance of both devices. The objective of the study is to compare the outcome of DF-LCP and DCS fixation in distal femoral fractures. Materials and Methods: This prospective comparative study was conducted in the Department of Orthopaedics, Sylhet MAG Osmani Medical College Hospital, Sylhet between January 2011 and December 2012. Thirty patients with AO type 33-B and 33-C fracture were selected and were divided randomly into group- $A$ and group-B by odd and even number. Dynamic condylar screw (DCS) fixation was used in group-A and distal femoral locking compression plate (DF-LCP) fixation in group- $B$. Results: DCS group [9 male, 6 female; mean age, $44.9 \pm 12.9$ years $]$ and $D F-L C P$ group $[10$ male, 5 female; mean age, $42.6 \pm 15.7)$ years $]$ were similar in age $(p=0.660)$ and sex ( $p=0.705$ ). The total operation (minutes) [92.3 \pm 7.5 versus $90.4 \pm 6.9 ; p=0.484]$, length of postoperative hospital stay (days) $[6.0 \pm 0.9$ versus $5.9 \pm 0.9 ; p=0.695]$ and union time (weeks) $[20.6 \pm 5.0$ versus $18.7 \pm 3.3$ weeks; $p=0.238]$ did not differ significantly between two groups. Total complications [6 (40.0\%) versus 4 (26.7\%); $p=0.439$ ] was also similar in both groups. Functional outcome was excellent in $13.3 \%$, good in $33.3 \%$, fair in $33.3 \%$ and poor in $20.0 \%$ cases in DCS group; while excellent in $53.3 \%$, good in $20.0 \%$ fair in $6.7 \%$ and poor in $20.0 \%$ of cases in DF-LCP group; different was not significant $(p=0.080)$. Conclusion: Dynamic condylar screw with plate and distal femoral locking compression plate fixation are equally effective for achieving satisfactory union and functional outcome in AO type 33-B, 33-C fracture distal femur.
\end{abstract}

Keywords: Dynamic condylar screw, Locking compression plate, Distal femur fracture.

Number of Tables: 03; Number of References: 20; Number of Correspondence: 08.

*1. Corresponding Author:

Dr. Md. Gulam Mustofa

Assistant Professor, Department of Orthopedics President Abdul Hamid Medical College, Kisoregonj. Email: dr.mustofamanik@gmail.com Mobile:01711030003

2. Dr. Chowdhury Foyzur Rob Senior Consultant, Department of Orthopedics Al-Haramin Hospital Pvt. Ltd., Sylhet.

3. Dr. Md. Kamrul Alam

Assistant Professor, Department of Orthopedics Sylhet MAG Osmani Medical College, Sylhet.

4. Dr. Akhlas Bhuiyan Student of MS in Orthopaedics Course Sylhet MAG Osmani Medical College, Sylhet.

5. Dr. Habibur Rahman Chowdhury

Senior Medical Officer

Department of Orthopaedics Al-Haramain Hospital Pvt. Ltd., Sylhet.

6. Dr. Sahel Ahmed Khan

Senior Medical Officer, Department of Orthopaedics Al-Haramain Hospital Pvt. Ltd., Sylhet.

7. Dr. Tanvir Ahmed

Senior Medical Officer, Department of Orthopaedics Al-Haramain Hospital Pvt. Ltd., Sylhet.
Introduction:

Distal femur fractures are typically complex, frequently comminuted and intra-articular, and they often involve osteoporotic bone. Understanding the inherent characteristics of distal femoral fracture as well as the principles and challenges of management is important in optimizing outcomes. Treatment goals are to restore axial alignment, anatomic reduction of the joint surface, minimize joint stiffness by allowing early mobilization, all with minimal soft-tissue disruption and to preserve the function of the extremity ${ }^{1}$. Surgical fixation has consistently demonstrated better outcomes than has nonsurgical management, including improved alignment, union, knee motion, and functional outcome $\mathrm{e}^{1,2}$.

Goals for treatment of distal femoral fractures of AO type 33-B (partial articular) and 33-C (complete articular) are anatomical alignment, stable fixation, rapid mobilization and early functional rehabilitation of the knee. Open reduction and internal fixation of these difficult fractures are justified only if (I) the joint surfaces can be restored anatomically, (II) fixation is sufficiently rigid that external immobilization is not required and (III) rigidity of fixation is sufficient to allow early and active motion of the knee joint ${ }^{3}$. As orthopaedic surgery has evolved, trends in treatment of supracondylar and intercondylar femoral fractures now more commonly involve operative management ${ }^{4}$.

Dynamic condylar screw provides freedom in the plane of flexion and extension, hence is technically less demanding than fixed angle 
device. It provides interfragmentary compression and also gives good purchase in osteoporotic bone ${ }^{3}$. Dynamic condylar screw fixation for distal femoral fractures achieves better functional outcomes and lower complication rates ${ }^{1,18}$.

Distal femoral locking compression plate (DF-LCP) allows both locking and compression screw fixation. Locking condylar plate fixation is indicated for intrarticular and extraaricular condylar fractures, buttressing of multi-fragmentary distal femoral fractures, bridging of high comminuted distal femoral fractures and treatment of distal femoral malunion ${ }^{5,16,17}$. Several studies showed a lower revision rate, less deformity and better morbidity in patients with distal femoral fractures treated by DF-LCP $6,7,20$

Though many centres throughout the world are practicing DF-LCP for fixation but less effort is observed in our country to evaluate the outcome of intercondylar fracture of femur fixation with DF-LCP in comparison to fixation by DCS and Plate. The distinction between DCS and DF-LCP fixation in AO type 33-B, 33-C fractures naturally lead to the question of which achieves the best outcome. If the functional outcome of the DF-LCP fixation in spite of some limitations overshadows the outcome of fixation by DCS and Plate in AO-type 33-B, 33-C fractures, and then it will end the therapeutic dilemma in our orthopaedic arena regarding the treatment of displaced, intraarticular distal fractures of femur. This study was designed to compare the outcome of DF-LCP and DCS fixation for AO type 33-B, 33-C fracture of the distal femur ${ }^{19}$.

\section{Materials and Methods:}

This prospective comparative study was conducted in the Department of Orthopaedics, Sylhet MAG Osmani Medical College Hospital, Sylhet during the period between January 2011 and December 2012. Thirty patients with closed fractures distal femur fracture were included. Inclusion criteria were (1) intercondylar fracture of distal femur (AO type 33-B and 33-C fractures) within 3 weeks of injury, (2) aged between 18 and 90 years irrespective of sex, (3) polytrauma, (4) osteoporotic fractures, (5) ambulant patients (all patients had independent walking capability with or without a walking aid before fracture) and (6) prove consent to enrolled in the study. Exclusion Criteria were (1) other type of intercondylar fractures except AO type 33-B, 33-C, (2) AO type 33-B3 and 33-C3, (3) pathological fracture except osteoporosis and (4) presence of infection. Diagnosis of AO type 33-B and 33-C fractures were confirmed by $\mathrm{X}$-ray of the affected thigh including the knee joint anterio-posteror (A/P) and lateral views and in some cases by CT scan of the knee.

\section{Procedure of data collection}

All patients with history of Road Traffic Accident (RTA) or simple fall were evaluated from history clinical examination and radiological investigations. Selection criteria were applied and those who fulfilled the inclusion criteria were included in this study. In this way 30 patients with intercondylar fracture of distal femur (AO type 33-B and 33-C fractures) were selected. They were divided randomly into group-A and group-B each comprised 15 patients. Every odd number of patient was taken as group-A and even number was taken as group-B. DCS fixation was done in patients of group-A and DF-LCP fixation in group-B. All patients were examined and declared fit by the anesthetists for fixation of intercondylar fractures of distal femur. After proper antibiotic prophylaxis (Preoperatively cefuroxime $1.5 \mathrm{gm} \mathrm{I} / \mathrm{V}$ followed by $750 \mathrm{mg}$ I/V 8 hourly for 3 doses and then orally 500mg 12 hourly for 5 days) DCS and DF-LCP fixation was done via lateral parapatellar (Modified Swashbuckler) approach using the recommended surgical technique for each implant. For DCS surgery, at the junction of anterior $1 / 3 \mathrm{rd}$ and posterior $2 / 3 \mathrm{rd}$ of the longest AP dimension, a $\mathrm{K}$-wire was inserted perpendicular to the lateral condyle of the femur. K-wire in the joint and the patellar groove was used as a guide. A lag screw, with the required length was inserted over the guide $\mathrm{K}$-wire. Once in place, a side plate was applied in the distal fragment, with at least 8 holes. In the anatomical reduction, plate was then fitted to the shaft of femur with $4.5 \mathrm{~mm}$ cortical screws and a couple of cancellous screws were attached into the intercondylar region. For distal femoral locking compression plate, the mode of approach was a lateral parapatellar with significant intercondylar comminution, coronal plane fractures or both. Temporary fixation was done by $2 \mathrm{~mm} \mathrm{~K}$-wire. Inter-fragmentary lag in the articular fragments was achieved by $6.5 \mathrm{~cm}$ cannulated cancellous screws placed anterior and posterior to the plate, which was then slid to lace and fixed with locking screws to the articular block. Stab incisions at the screw sites were given and the plate was secured to the diaphyseal portion.

Follow up: The patient undergoing DCS or DF-LCP fixation were to be informed about mobilization technique and were allowed to sit on the bed 2nd day. Quadriceps isometric exercises and active assisted passive knee flexion exercises as tolerated on 2 nd post operative day. Ambulation with crutches was began when the patient leg is straightened and initiate progressive gait training without bearing weight after 3 months. Every patient was discharged on the 5 th post operative day. Post discharge follow-up were done at 3 weeks, 6 weeks, 3 months, 6 months and evaluations to be done on the basis of Knee Society Score ${ }^{8}$. Stitches of all the operative patients were removed on 3rd week during first follow up. Non weight bearing crutch walking was recommended immediately after surgery up to 3 months. The initiation of partial weight bearing was after 3 months and full weight bearing after 6 months. The initiation of full weight bearing was determined by a review of patient symptoms. 
Radiographic appearance and healing of associated injuries, time to advance to full weight bearing and final range of motion were documented for all patients. Complications of fixation failure, infection, and secondary surgical interventions were also documented.

Statistical Analysis: Data were processed and analysed with the help of computer program SPSS (Statistical package for social sciences) 16 version. Quantitative data were analyzed by mean and standard deviation; and comparison was done between two groups by unpaired t-test. Qualitative data were analyzed by rate, ratio, and percentage; and comparison was done between two groups by Chi-Square test. A probability (p) value of $<$ $0.05(p<0.05)$ was considered statistically significant.

Ethical Consideration: An approval of the study protocol was obtained from the Ethical Review Committee of Sylhet M.AG. Osmani Medical College Sylhet before the commencement of the study and informed written consent was obtained from every patient after explaining the options of treatment, ultimate outcome, possible side effects and complications of operative procedures.

\section{Results:}

The age of the patients ranged from 22 to 70 years with the mean age of $43.7 \pm 14.2$ years. The mean age of the patients in both groups was almost identical $(\mathrm{t}=0.445$; $\mathrm{p}=0.660$ ). Male preponderance with male to female ratio was 1.7:1 [Table-I].

Table-I: Distribution of the patients by baseline characteristics.

\begin{tabular}{llll}
\hline $\begin{array}{c}\text { Baseline } \\
\text { characteristics }\end{array}$ & $\begin{array}{c}\text { Group-A } \\
(\mathrm{n}=15)\end{array}$ & $\begin{array}{c}\text { Group-B } \\
(\mathbf{n}=15)\end{array}$ & P value \\
\hline Age & $3(20.0)$ & $4(26.7)$ & ${ }^{*} \mathrm{p}=0.799$ \\
21-30 years & $2(13.3)$ & $3(20.0)$ & \\
31-40 years & $5(33.3)$ & $4(26.7)$ & \\
41-50 years & $3(20.0)$ & $1(6.7)$ & \\
51-60 years & $2(13.3)$ & $3(20.0)$ & \\
$\quad$ 61-70 years & $44.9 \pm 12.9$ & $42.6 \pm 15.7$ & ${ }^{*} \mathrm{p}=0.660$ \\
$\quad$ Mean in years & & & \\
Sex & $9(60.0)$ & $10(66.7)$ & ${ }^{*} \mathrm{p}=0.705$ \\
$\quad$ Male & $6(40.0)$ & $5(33.3)$ & \\
$\quad$ Female & & & \\
Cause of injury & $10(66.7)$ & $9(60.0)$ & $* \mathrm{p}=0.591$ \\
$\quad$ RTA & $5(33.3)$ & $5(33.3)$ & \\
$\quad$ Trauma & $0(0.0)$ & $1(6.7)$ & \\
$\quad$ Fall from height & & & \\
\hline
\end{tabular}

*Chi-Square test and Unpaired $t$ test were employed to analyze the data. Figure in the parenthesis indicates corresponding percentage. Mean was expressed as mean \pm standard deviation.

Regarding cause of injury, road traffic accident (RTA) is the common cause $(63.3 \%)$, other causes were trauma $(33.3 \%)$ and fall from height $(3.3 \%)$. The cause of injury between groups did not differed statistically significant $\left(\chi^{2}=1.053 ; p=0.591\right)$ [Table-I].

The mean operation time was $[92.3 \pm 7.5$ (range, 80-100) minutes versus $90.4 \pm 6.9$ (range, 80-105) minutes, $\mathrm{t}=0.710 ; \mathrm{p}=0.484]$; length of postoperative hospital stay $[6.0 \pm 0.9$ days versus $5.9 \pm 0.9$ days, $t=0.397, p=0.695]$ and union time $[20.6 \pm 5.0(12-26)$ weeks versus $18.7 \pm$ 3.39 (12-28) weeks, $\mathrm{t}=1.210, \mathrm{p}=0.238$ ] did not differ significantly between two groups.

Post operative complications were similar in both groups such as superficial wound infection, postoperative stiffness, varus deformity and Implant failure were similar in both groups $(\mathrm{p}>0.05)$ [Table-II].

Functional outcome was excellent in $13.3 \%$, good in $33.3 \%$, fair in $33.3 \%$ and poor in $20.0 \%$ cases in the group-A. In group-B functional outcome was excellent in $53.3 \%$, good in $20.0 \%$ fair in $6.7 \%$ and poor in $20.0 \%$ of cases. The functional outcome of either method of fixation was almost similar $(\chi 2=6.767 ; p=0.080)$ [Table-III].

Table-II: Distribution of patients by post operative complications

\begin{tabular}{llll}
\hline \multicolumn{1}{c}{ Complications } & $\begin{array}{c}\text { Group-A } \\
(\mathrm{n}=15)\end{array}$ & $\begin{array}{c}\text { Group-B } \\
(\mathrm{n}=15)\end{array}$ & P value \\
\hline Superficial wound infection & $3(20.0)$ & $2(13.3)$ & $\mathrm{p}=0.624$ \\
Postoperative stiffness & $4(26.7)$ & $3(20.0)$ & $\mathrm{p}=0.666$ \\
Varus deformity & $1(6.7)$ & $2(13.3)$ & $\mathrm{p}=0.543$ \\
Implant failure & $2(13.3)$ & $1(6.7)$ & $\mathrm{p}=0.543$ \\
Total complications & $6(40.0)$ & $4(26.7)$ & $\mathrm{p}=0.439$ \\
\hline
\end{tabular}

*Chi-Square test was employed to analyze the data. Figure in the parenthesis indicates corresponding percentage. Individual complications were more due to multiple complication of occurred in some of the patient.

Table-III: Distribution of respondents by outcome

\begin{tabular}{llll}
\hline Functional outcome & $\begin{array}{c}\text { Group-A } \\
(\mathrm{n}=15)\end{array}$ & $\begin{array}{c}\text { Group-B } \\
(\mathrm{n}=15)\end{array}$ & P value \\
\hline Excellent & $2(13.3)$ & $8(53.3)$ & \\
Good & $5(33.3)$ & $3(20.0)$ & $\mathrm{p}=0.080$ \\
Fair & $5(33.3)$ & $1(6.7)$ & \\
Poor & $3(20.0)$ & $3(20.0)$ & \\
Total & $15(100.0)$ & $15(100.0)$ & \\
\hline
\end{tabular}

*Chi-Square test was applied to analyze the data. Figure in the parenthesis indicates corresponding percentage.

\section{Discussion:}

In this study the age of the patients ranged from 22 to 70 years with the mean age of $43.7 \pm 14.2$ years. The mean age of the patients in DCS group and DF-LCP group was almost identical $(p=0.660)$. This result was supported by Yeap and Deepak, ${ }^{6}$ that the age of the patients ranged from 15 to 85 years with a mean age of 44 years. Several other studies supported this result ${ }^{4,7,9}$.

In the present study $63.7 \%$ patients were male and $36.7 \%$ patients were female with male to female ratio of $1.7: 1$. There was no significant difference of between two groups $(p=0.715)$. This result was correlated with the study of Yeap and Deepak, ${ }^{6}$ that $63.6 \%$ of patients were male and $36.4 \%$ of patients were female in their series. Male preponderance of distal femoral fracture reported in other studies $^{4,7,9}$. Males were more exposed to severe injuries because of their outdoors work, serious traffic conditions and over speeding while females tend to spend more time indoors in a more conservative community.

Regarding cause of injury the current study showed that, 
road traffic accident (RTA) is the common cause $(63.3 \%)$ of distal femoral fracture, other causes were trauma $(33.3 \%)$ and fall from height $(3.3 \%)$. The cause of injury between groups did not differed statistically significant $(p=0.591)$. This result was in agreement with the study of Nayak et al. ${ }^{4}$ that the causes of injury were vehicular accidents (77.4\%), falls (19.4\%), and assault (3.2\%). RTA was the more frequent mechanisms of injury described in several studies ${ }^{6,9-12}$. This high incidence of RTA in this study was attributed to the difficult traffic conditions and over speeding ${ }^{13}$.

In this study the mean operation time was $92.3 \pm 7.5$ minutes in DCS group; whereas the mean total operation time was $90.4 \pm 6.9$ minutes in DF-LCP group; difference was not significant $(p=0.484)$. Similar duration of surgery was reported in other studies ${ }^{3,13}$.

In this study the mean length of postoperative hospital stay in this study was $6.0 \pm 0.9$ days in the patients in DCS group and was $5.9 \pm 0.9$ days in DF-LCP group. The mean length of postoperative hospital stay of both groups were almost similar $(p=0.695)$. Hakeem et al. ${ }^{5}$ reported the average hospital stay was 8 days (range 4-15 days) in their series of patients treated with DCS; while Nayak et al. ${ }^{4}$ found the mean length of hospital stay was 9 (ranged 6 to14) days in their series of patients treated with LCP.

In the current study the mean union time was $20.6 \pm 5.0$ weeks in the patients in DCS group and was $18.7 \pm 3.3$ weeks in DF-LCP group. The mean union time of both groups were almost similar $(\mathrm{p}=0.238)$. This result correlated with other studies. ${ }^{6,7,14}$.

In the present study post operative complications were similar in both groups such as superficial wound infection, postoperative stiffness, varus deformity and implant failure ${ }^{17,19}$. Ali and Shahabuddin, ${ }^{15}$ found that overall infection rate was $5.71 \%$, stiffness of knee joint in $17.14 \%$, limb shortening up to $1.5 \mathrm{~cm}$ in $5.71 \%$ in their patients treated with DCS. Supanich, ${ }^{7}$ found varus deformity $>5^{0}$ in $22 \%$, knee stiffness (flexion $<90^{\circ}$ ) in $4 \%$ and leg length discrepancy $>2 \mathrm{~cm}$ in $4 \%$ of their patient treated with DCS; while varus deformity $>5^{0}$ was in $15 \%$, knee stiffness (flexion $<90^{\circ}$ ) in $4 \%$ and leg length discrepancy $>2 \mathrm{~cm}$ in $4 \%$ of their patient treated with DF-LCP.

In this study functional outcome was excellent in $13.3 \%$, good in $33.3 \%$, fair in $33.3 \%$ and poor in $20.0 \%$ cases in the DCS group; while in DF-LCP group functional outcome was excellent in $53.3 \%$, good in $20.0 \%$ fair in $6.7 \%$ and poor in $20.0 \%$ of cases. The functional outcome of either method of fixation was almost similar $(\mathrm{p}=0.080)$.

Ali and Shahabuddin, ${ }^{15}$ found that outcome was excellent in $57.1 \%$, good in $17.1 \%$, moderate in $8.6 \%$ and poor in $17.1 \%$ of their patient treated with DCS. Sharma, ${ }^{13}$ reported the overall results were excellent in $32 \%$ of patients, good in $36 \%$ patients, moderate in $12 \%$ of patients and poor in $20 \%$ of patients of their series of patients treated with DCS. Dar et al. ${ }^{14}$ found that outcome was excellent in $48 \%$, good in $30 \%$, fair in $17 \%$ and poor in $5 \%$ of their patient treated with DCS. Yeap and Deepak, ${ }^{6}$ found excellent in $36.4 \%$ good in $36.4 \%$, fair in $18.2 \%$ and failure in $9.1 \%$ of patients treated with DF-LCP. Supanich, ${ }^{7}$ found that outcome was excellent in $48 \%$, good in $30 \%$, fair in $17 \%$ and poor in $5 \%$ of their patient treated with DCS; while excellent in $56 \%$, good in $33 \%$, fair in $7 \%$ and poor in $4 \%$ of their patient treated with DF-LCP and difference in the outcome between two groups was not statistically significant $(\mathrm{p}=0.961)$.

\section{Conclusion:}

It is concluded that for patients requiring management of AO type 33-B, 33-C fracture distal femur, dynamic condylar screw with plate and distal femoral locking compression plate fixation are equally effective for achieving satisfactory union and functional outcome. However a multicenter randomized control trial using C-ARM and a large sample size should be conducted to evaluate the DCS and PF-LCP in the management of patients with AO type 33-B, 33-C fractures.

\section{Conflict of Interest: None.}

\section{Acknowledgement:}

The authors thank to Dr. Md. Tabibul Islam, MD (Dermatology \& Venereology), Assistant Professor, Department of Dermatology \& Venereology, Sylhet MAG Osmani Medical College, Sylhet for his assistance in the analysis of data.

The following limitations were faced during this study (1) This study was conducted in a single tertiary care hospital, (2) sample size was small and (3) unavailability of C-ARM facilities in the study place duration of operation time was longer which may affect the complication as well as outcome.

\section{References:}

1. Gwathmey FW Jr, Jones-Quaidoo SM, Kahler D, Hurwitz S, Cui Q. Distal Femoral Fractures: Current Concepts. J Am Acad Orthop Surg. 2010; 18(10): 597-607. https://doi.org/10.5435/00124635-201010000-00003

\section{PMid:20889949}

2. Butt MS, Krikler SJ, Ali MS. Displaced fractures of the distal femur in elderly patients: Operative versus non-operative treatment. J Bone Joint Surg Br. 1996; 78(1): $110-4$.

\section{https://doi.org/10.1302/0301-620X.78B1.0780110}

\section{PMid:8898139}

3. Paige WA. Fractures of Lower Extremity. In: Canale ST, editor. Campbell's Operative Orthopaedics. 11th ed. Philadelphia: Mosby; 2008; 3: 3170-90. 
4. Nayak RM, Koichade MR, Umre AN, Ingle MV. Minimally invasive plate osteosynthesis using a locking compression plate for distal femoral fractures. J Orthop Surg. 2011; 19(2): 185-90.

https://doi.org/10.1177/230949901101900211

PMid:21857042

5. Hakeem A, Khan NU, Khan MI, Ullah F. Dynamic condylar screw (DCS) fixation in treatment of supracondylar fracture of distal femur. Rawal Med J. 2010; 35: 45-7.

https://www.bibliomed.org/mnsfulltext/27/27-1301602666. pdf?1603769928.

6. Yeap EJ, Deepak AS. Distal Femoral Locking Compression Plate Fixation in Distal Femoral Fractures: Early Results. Malaysian Orthop J. 2007; 1(1): 12-7.

https://doi.org/10.5704/MOJ.0705.004

7. Supanich V. Results of the Treatment of Type-C Distal Femoral Fractures using Four Different Implants: Condylar Blade Plate, Dynamic Condylar Screw, Condylar Buttress Plate, and Distal Femoral Locking Plate. Thai J Orthop Surg. 2012; 36(1-2): 8-15.

8. Scuderi GR, Bourne RB, Noble PC, Benjamin JB, Lonner JH, Scott WN. The new Knee Society Knee Scoring System. Clin Orthop Relat Res. 2012; 470(1): 3-19. https://doi.org/10.1007/s11999-011-2135-0

PMid:22045067 PMCid:PMC3237971

9.Petsatodis G, Chatzisymeon A, Antonarakos P, Givissis P, Papadopoulos P, Christodoulou A. Condylar buttress plate versus fixed angle condylar blade plate versus dynamic condylar screw for supracondylar intra-articular distal femoral fractures. J Orthop Surg. 2010; 18(1): 35-8.

https://doi.org/10.1177/230949901001800108

PMid:20427831

10. Shewring DJ, Meggitt BF. Fractures of the Distal Femur Treated with the AO Dynamic Condylar Screw. J Bone Joint Surg Br. 1992;74:122-5.

https://doi.org/10.1302/0301-620X.74B1.1732239

PMid:1732239

11.Leung KS, Shen WY, So WS. Interlocking Intramedullary Nailing for Supracondylar and Intercondylar Fractures of the Distal Part of the Femur. J Bone Joint Surg Am. 1991; 73(3): 332-40.

https://doi.org/10.2106/00004623-199173030-00003

PMid:2002070
12.Kim J-W, Oh C-W, Kyung H-S, Min W-K, Yoon S-H. Factors Affecting the Results of Distal Femoral Fractures Treated by Retrograde Intramedullary Nailing. Chin J Reparat Reconstr Surg. 2009; 23(11): 1311-5.

13. Sharma A. Surgical management of distal femoral fractures in adults using dynamic condylar screw. Dissertation (Master of Surgery in Orthopaedics). Rajiv Gandhi University of Health Sciences, Bangalore, Karnataka; 2006.

14.Dar GH, Tak SR, Kangoo KA, Halwai MA. Bridge plate osteosynthesis using dynamic condylar screw (DCS) or retrograde intramedullary supracondylar nail (RIMSN) in the treatment of distal femoral fractures: comparison of two methods in a prospective randomized study. Ulus Travma Acil Cerrahi Derg. 2009; 15(2):148-53.

15.Ali I, Shahabuddin. Surgical outcome of supracondylar and intercondylar fractures femur in adults Treated with dynamic condylar screw. JPMI. 2011; 25(1): 49-55. https://jpmi.org.pk/index.php/jpmi/article/viewFile/1119/10 28

16.Heiney, J.P., Barnett, M.D., Vrabec, G.A., et al. Distal femoral fixation: A biomechanical comparison of trigen retrograde intramedullary (I.M.) nail, Dynamic Condylar Screw (DCS), and Locking Compression Plate (LCP) condylar plate. J Trauma. 2009; 66:443-9.

https://doi.org/10.1097/TA.0b013e31815edeb8

PMid:19204519

17.Henderson, C.E., Kuhl, L.L., Fitzpatrick, D.C., et al. Locking plates for Distal Femur Fractures: Is there a Problem With Fracture Healing? J Orthop Trauma. 2011; 25: S8-14.

https://doi.org/10.1097/BOT.0b013e3182070127

PMid:21248560

18.Motten, T.L., Gupta, R.K. Kalsotra, N., Kamal, et al. The role of dynamic condylar screw in the management of fractures of the distal end of femur. The Internet Journal of Orthopaedic Surgery. 2010; 17(2).

https://doi.org/10.5580/1399

19.Stover, M. Distal femoral fractures: current treatment, results and problems. Injury. 2001; 32, SC3-13.

https:/doi.org/10.1016/S0020-1383(01)00179-6

20.Subbaiah, G.P. Surgical management of closed fractures of distal end of femur or proximal end of tibia using locking compression plate-a prospective study. Dissertation (MS Orthopaedics). 2010. 